\title{
Sagittal split ramus osteotomy, intraoral vertical ramus osteotomy, and lateral corticectomy for asymmetric mandibular prognathism
}

\author{
Joo Young Lee, Se Jin Han \\ Department of Oral and Maxillofacial Surgery, College of Dentistry, Dankook University, Cheonan, Korea
}

\begin{abstract}
J Korean Assoc Oral Maxillofac Surg 2021;47:249-256)
Objectives: The purpose of this study was to evaluate the postoperative anteroposterior stability and improvements in facial asymmetry after performing LeFort I osteotomy in the maxilla, sagittal split ramus osteotomy (SSRO) and intraoral vertical ramus osteotomy (IVRO) in the mandible, and lateral corticectomy on the IVRO side.

Materials and Methods: From July 2009 to October 2018, a retrospective analysis was performed on 11 subjects. Lateral cephalometric radiograph was performed preoperatively (T0), postoperatively (T1), and at 12 months of follow-up (T2), and the B point distance was measured. Posteroanterior cephalometric radiograph was performed preoperatively (S0) and at 12 months of follow-up (S1) and was used to measure five indicators (Ag angle, $\mathrm{M}-\mathrm{Ag}, \mathrm{Co}-\mathrm{Ag}, \mathrm{Co}-\mathrm{Me}$, and $\mathrm{Ag}-\mathrm{Me}$ ) of facial asymmetry.

Results: The B point distances for T0 and T1 were significantly different $(P=0.007)$, whereas those for $\mathrm{T} 1$ and $\mathrm{T} 2$ were not significantly different $(P=0.1)$. In addition, there was a significant difference between the B point distances of T2 and T0 $(P=0.026)$. Comparison of the facial asymmetry indicators before and after surgery showed a significant difference for all indicators between $\mathrm{S} 0$ and $\mathrm{S} 1$ : the $P$-values of Ag angle, M-Ag, Co-Ag, Co-Me, and Ag-Me were $0.003,0.003,0.008,0.006$, and 0.004 , respectively. The $Z$ value was based on negative ranks.

Conclusion: There was no significant difference in the B point distances from postoperation to the 12-month follow-up. However, there were significant differences in all five indicators related to facial asymmetry before and after surgery. The values for the five indicators of facial asymmetry all increased postoperatively.
\end{abstract}

Key words: Prognathism, Facial asymmetry, Sagittal split ramus osteotomy

[paper submitted 2021. 4. 20 / revised 2021. 5. 24 / accepted 2021. 5. 31]

\section{Introduction}

Many cultural and societal values emphasize the appearance of individuals, which increases individual interest in appearances. In particular, the main factors that affect facial appearance are asymmetry and mandibular prognathism. A positive correlation among social pressure, physical dissatisfaction related to appearance, and mental health has been reported, particularly in younger generations ${ }^{1}$. Moreover, a study reported that symmetrical faces are perceived as more

\section{Se Jin Han}

Department of Oral and Maxillofacial Surgery, College of Dentistry, Dankook University, 119 Dandae-ro, Dongnam-gu, Cheonan 31116, Korea

TEL: +82-41-550-0271

E-mail:hanimplant@dankook.ac.kr

ORCID: https://orcid.org/0000-0003-4949-4462

(c) This is an open-access article distributed under the terms of the Creative Commons Attribution Non-Commercial License (http://creativecommons.org/ licenses/by-nc/4.0/), which permits unrestricted non-commercial use, distribution, and reproduction in any medium, provided the original work is properly cited.

Copyright (C) 2021 The Korean Association of Oral and Maxillofacial Surgeons. attractive ${ }^{2}$.

Mandibular prognathism is more prevalent in East Asian countries, such as Korea, Japan, and China, than in the West. It is characterized by a long face, a large gonial angle, anterior open bite, incomplete lip closure, and a concave appearance. A face is considered asymmetrical when the dental midline deviation is $2.2 \mathrm{~mm}$ or more ${ }^{3}$, and facial asymmetry is common in the general population and increases toward the mandible ${ }^{2,4-7}$. However, mandibular prognathism cannot be corrected with conventional orthodontic treatments but requires orthognathic surgery.

Sagittal split ramus osteotomy (SSRO) is the most widely used surgical method for mandibular prognathism. It is advantageous because it allows smooth and rapid bone healing by rigid internal fixation through wide contact between the cancellous bones. However, treatment of asymmetry mandibular prognathism with bilateral SSRO (BSSRO) requires rotation of the distal segment of the mandible. Therefore, the gap between the proximal and distal segments widens. 
Fixation results in an inwardly displaced proximal segment, causing poor postoperative stability ${ }^{8-11}$. In addition, intraoral vertical ramus osteotomy (IVRO) is not optimal because it requires a longer healing period than that of SSRO, although the temporomandibular joint (TMJ) is physiologically well positioned with this approach.

In this study, we combined the SSRO and IVRO approaches to achieve a shorter healing period and stable TMJ position in patients with mandibular prognathism. Additionally, we performed lateral corticectomy on the IVRO side to resolve facial asymmetry. The purpose of this study was to evaluate the postoperative anteroposterior stability and improvement of facial asymmetry using a combination of IVRO, SSRO, and lateral corticectomy on the IVRO side in patients with asymmetric mandibular prognathism.

\section{Materials and Methods}

The patients' records for admission to the Department of Oral and Maxillofacial Surgery at Dankook University Dental Hospital for treatment of asymmetric mandibular prognathism from July 2009 to October 2018, were reviewed after obtaining approval from the Institutional Review Board of Dankook Dental University Hospital (DKUDH IRB 2020-11004).

\section{Subjects}

This retrospective study was conducted based on clinical photos, information, and radiographs of 11 patients who visited Dankook University Dental Hospital between July 2009 and October 2018. The patients were diagnosed with mandibular prognathism accompanied by facial asymmetry and underwent surgery at the hospital based on posteroanterior
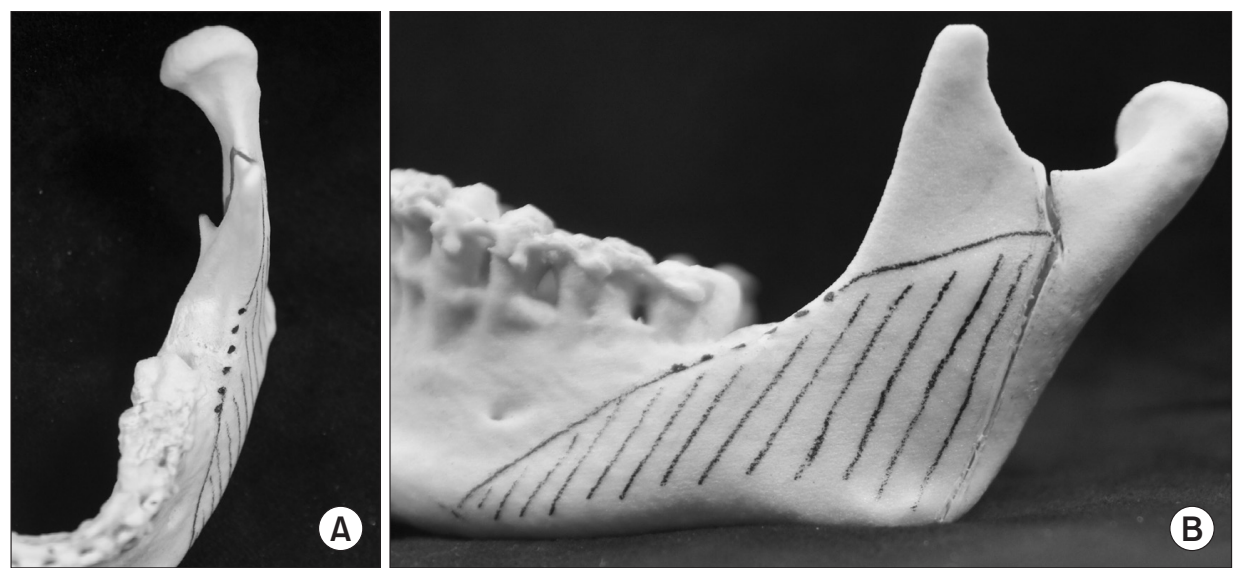

Fig. 1. A. Several holes are made by using bur on the oblique ride line of mandible. B. Adequate cortical bones are removed by lateral corticectomy procedure.

Joo Young Lee et al: Sagittal split ramus osteotomy, intraoral vertical ramus osteotomy, and lateral corti-
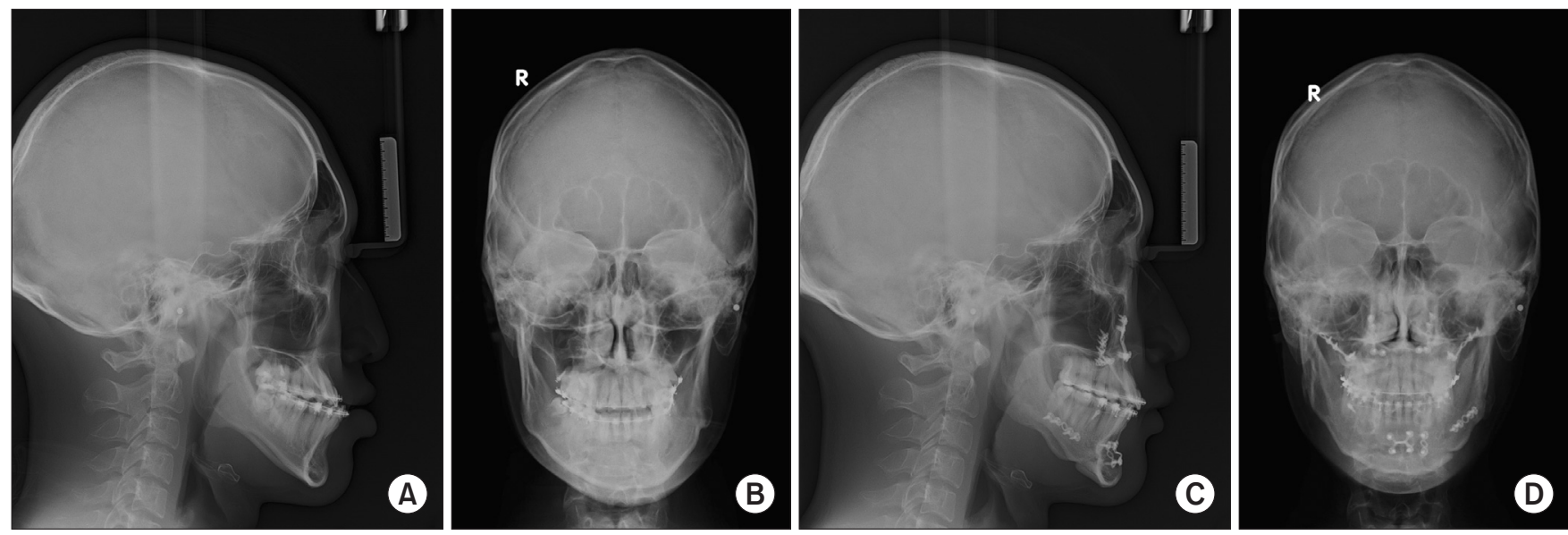

Fig. 2. A. Preoperative posteroanterior (PA) cephalometric. B. Preoperative lateral cephalometric. C. Postoperative PA cephalometric. D. Postoperative lateral cephalometric.

Joo Young Lee et al: Sagittal split ramus osteotomy, intraoral vertical ramus osteotomy, and lateral corticectomy for asymmetric mandibular prognathism. J Korean Assoc Oral Maxillofac Surg 2021 
cephalometric radiograph (PA Ceph) and lateral cephalometric radiograph (Lat Ceph). None of the patients had underlying disease. There were six male and five female patients with an average age of 19.5 years (range, 18-23 years). Intermaxillary fixation was performed for approximately 28.1 days (range, 23-37 days), and the average menton deviation was $6.95 \mathrm{~mm}$ (range, 2.8-16.6 mm).

\section{Surgical methods}

An oral and maxillofacial surgeon performed LeFort I osteotomy on the maxilla and SSRO, IVRO, and lateral corticectomy on the IVRO side on the mandible. The surgical plan was based on a three-dimensional computed tomography model. All surgeries were performed using an intraoral approach. For lateral corticectomy, we defined the anterior, upper, and posterior boundaries as the posterior of the mental foramen, the part under the sigmoid notch, and the IVRO osteotomy line, respectively. Holes were created with a bur along the oblique ridge, and the boundaries were cut by connecting these holes with a reciprocating saw. The cortical bone was removed using a chisel in the gap made by this cut.
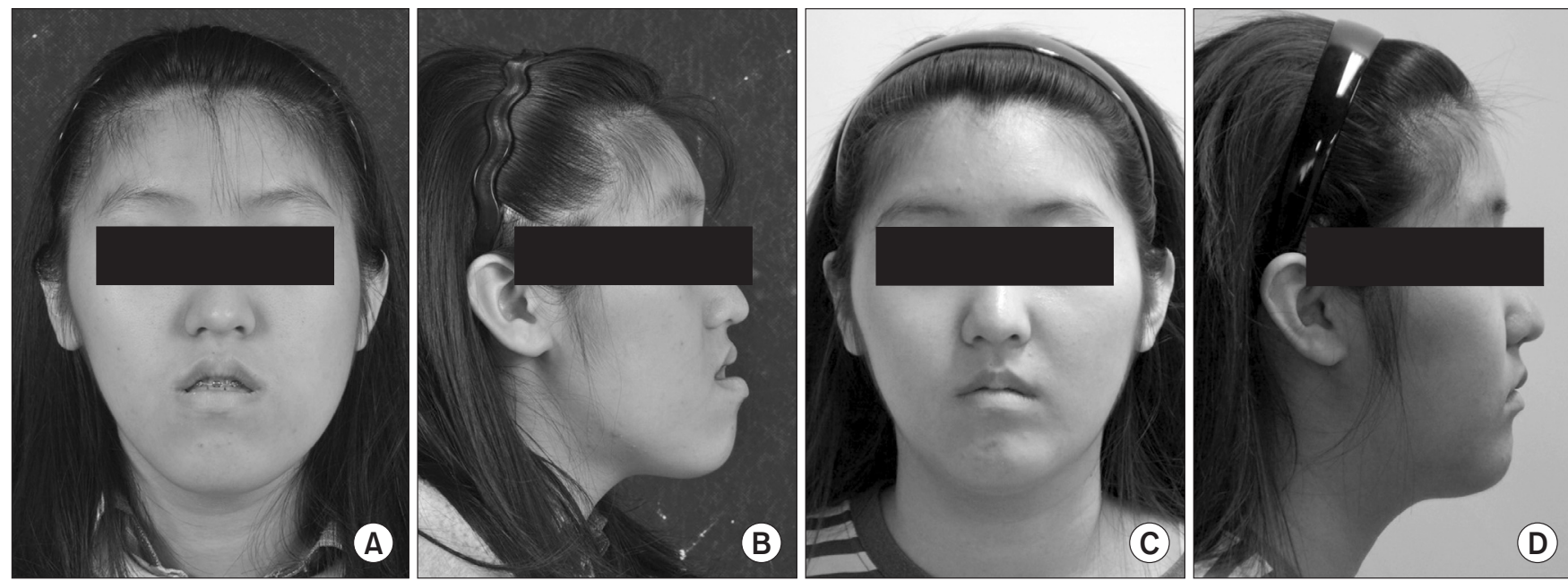

Fig. 3. A. Preoperative frontal facial photo. B. Preoperative lateral facial photo. C. Postoperative frontal facial photo. D. Postoperative lateral facial photo.

Joo Young Lee et al: Sagittal split ramus osteotomy, intraoral vertical ramus osteotomy, and lateral corticectomy for asymmetric mandibular prognathism. J Korean Assoc Oral Maxillofac Surg 2021
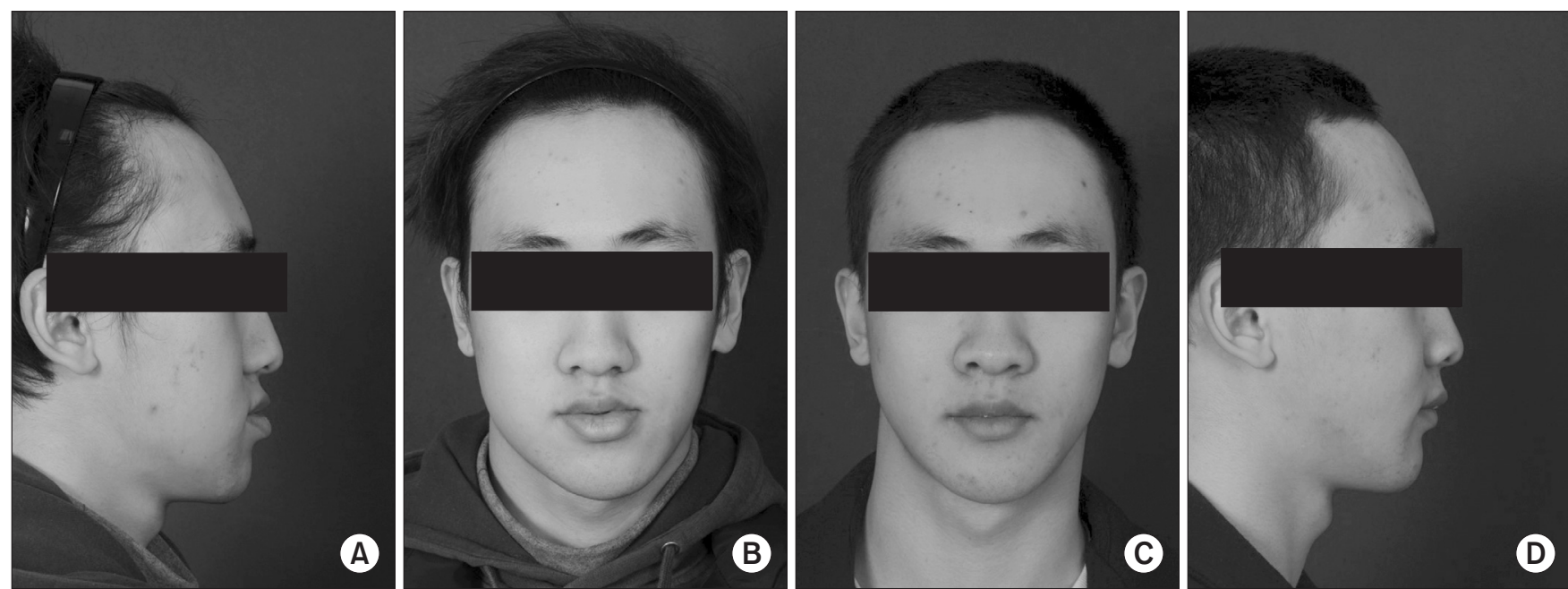

Fig. 4. A. Preoperative frontal facial photo. B. Preoperative lateral facial photo. C. Postoperative frontal facial photo. D. Postoperative lateral facial photo.

Joo Young Lee et al: Sagittal split ramus osteotomy, intraoral vertical ramus osteotomy, and lateral corticectomy for asymmetric mandibular prognathism. J Korean Assoc Oral Maxillofac Surg 2021 
(Fig. 1) Intermaxillary fixation was performed after surgery, followed by postoperative patient management. After discharge, the patients underwent periodic follow-up, during which clinical photographs and radiographs were recorded.

(Fig. 2-4)

\section{Study methods}

Standardized cephalometric radiographs were used for precise comparison. The Lat Ceph was used to evaluate postoperative anteroposterior stability, and PA Ceph was used to evaluate facial asymmetry. Preoperative Lat Ceph was

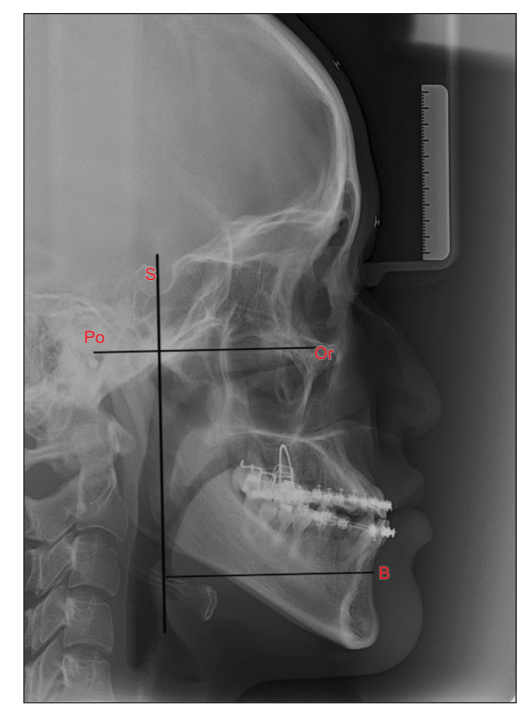

Fig. 5. Reference points and axes on lateral cephalometric radiograph. (S: sella turcica, Or: orbitale, Po: porion, B: B point, X-axis: Frankfort line, Y-axis: The line which is through the sella turcica and perpendicular to the Frankfort line)

Joo Young Lee et al: Sagittal split ramus osteotomy, intraoral vertical ramus osteotomy, and lateral corticectomy for asymmetric mandibular prognathism. J Korean Assoc Oral Maxillofac Surg 2021

Table 1. Postoperative anteroposterior stability and facial asymmetry evaluation

\begin{tabular}{cl}
\hline \multicolumn{1}{c}{ Measurement } & \multicolumn{1}{c}{ Definition } \\
\hline $\begin{array}{c}\text { Anteroposterior stability } \\
\text { B point distance }\end{array}$ & $\begin{array}{c}\text { The distance from the line through the } \\
\text { sella turcica and perpendicular to the } \\
\text { Frankfort line to the B point }\end{array}$ \\
$\begin{array}{c}\text { Facial asymmetry } \\
\text { Ag angle }\end{array}$ & $\angle$ Co-Ag-Me angle \\
Co-Ag length & From Co to Ag length \\
Ag-Me length & From Ag to Me length \\
Co-Me length & From Co to Me length \\
Ag distance & From MSR to Ag length \\
\hline
\end{tabular}

(Co: condylion, Ag: antegonion, Me: menton, MSR: mid-sagittal reference line)

Joo Young Lee et al: Sagittal split ramus osteotomy, intraoral vertical ramus osteotomy, and lateral corticectomy for asymmetric mandibular prognathism. J Korean Assoc Oral Maxillofac Surg 2021 set to T0, to T1 for postoperation, and to T2 at 12 months. Similarly, preoperation PA Ceph was set to S0, and that at the 12-month follow-up was S1.

The reference points for evaluating anteroposterior stability after surgery were the sella turcica (S), orbitale (Or), porion (Po), and B point. In the Lat Ceph, the Frankfort line was set as the $\mathrm{X}$-axis, and the line passing through the sella turcica perpendicular to the Frankfort line was set as the Y-axis.(Fig. 5) We set the distance from the Y-axis to the B point as the B point distance (Table 1) to evaluate postoperative anteroposterior stability and measured the difference in the distance to the B point (T2-T1) after surgery and at 12-month follow-up. To evaluate the statistical significance, we compared the Lat Cephs from pre-and postoperative (T0, T1), postoperative and 12-month follow-up (T1, T2), and at 12-month follow-up and preoperative (T2, T0) timepoints.

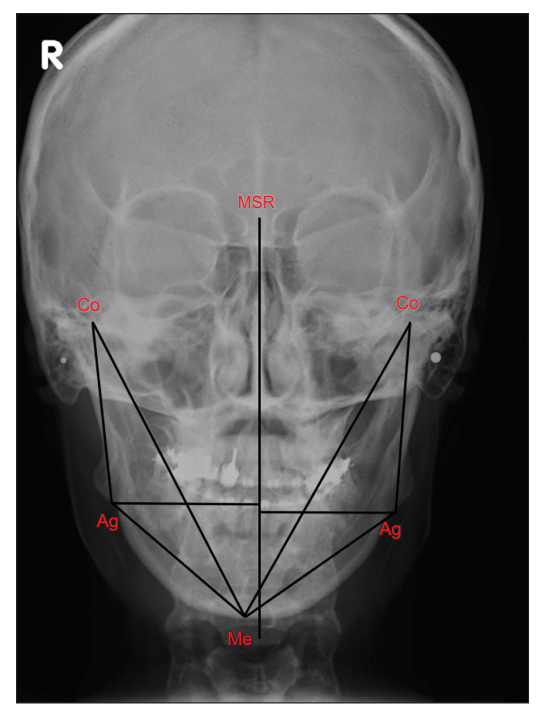

Fig. 6. Reference points and lines on posteroanterior cephalometric radiograph. (Co: condylion, Ag: antegonion, Me: menton, MSR: mid-sagittal reference line)

Joo Young Lee et al: Sagittal split ramus osteotomy, intraoral vertical ramus osteotomy, and lateral corticectomy for asymmetric mandibular prognathism. J Korean Assoc Oral Maxillofac Surg 2021

Table 2. Facial asymmetry indicators

\begin{tabular}{|c|c|}
\hline Indicator & Definition \\
\hline Ag angle $(\%)$ & $\mathrm{Ag}$ ' angle/Ag angle $\times 100$ \\
\hline MSR-Ag (\%) & MSR-Ag' distance/MSR-Ag distance $\times 100$ \\
\hline $\mathrm{Co}-\mathrm{Ag}(\%)$ & Co'-Ag' distance/Co-Ag distance $\times 100$ \\
\hline Co-Me $(\%)$ & Co'-Me' distance/Co-Me distance 100 \\
\hline $\mathrm{Ag}-\mathrm{Me}(\%)$ & Ag'-Me' distance/Ag-Me distance $\times 100$ \\
\hline
\end{tabular}

(Ag: antegonion, MSR: mid-sagittal reference line, Co: condylion, Me: menton, $\mathrm{Ag}^{\prime}, \mathrm{Co}^{\prime}, \mathrm{Me}^{\prime}$ : contralateral side of $\mathrm{Ag}, \mathrm{Co}, \mathrm{Me}$ ) Ag', $\mathrm{Co}^{\prime}, \mathrm{Me}$ '<Ag, $\mathrm{Co}, \mathrm{Me}$.

Joo Young Lee et al: Sagittal split ramus osteotomy, intraoral vertical ramus osteotomy, and lateral corticectomy for asymmetric mandibular prognathism. J Korean Assoc Oral Maxillofac Surg 2021 
To evaluate the improvement in facial asymmetry, condylion (Co), antegonion (Ag), menton (Me), and mid-sagittal reference (MSR) lines were used (Fig. 6), and five measurements were recorded.(Table 1) Values were measured from the left and right sides, and the small values were divided by larger values to obtain the ratios, noted as $\mathrm{Ag}$ angle, $\mathrm{Co}-\mathrm{Ag}$, Ag-Me, Co-Me, and MSR-Ag.(Table 2) Each indicator was compared performed preoperatively (S0) and postoperatively (S1). A single observer performed the measurements in duplicate, and the study was conducted using the average values. Reference points were set using Adobe Photoshop 2021 (Adobe, San José, CA, USA), and the length and angle were measured.

\section{Statistics methods}

The Wilcoxon signed-rank test was performed using the IBM SPSS Statistics program (ver. 25; IBM, Armonk, NY, USA). The values of (T0, T1), (T1, T2), and (T2, T0) at timepoints were evaluated to assess postoperative anteroposterior stability. For facial asymmetry, S0 and S1 were compared and evaluated for each indicator. A statistically significant difference was noted when the $P$-value was $<0.05$.

\section{Results}

\section{Postoperative anteroposterior stability}

The preoperative (Fig. 2. B) and postoperative (Fig. 2. D) radiographs indicated minimal changes in condylar position following surgery. Table 3 summarizes the average values of

Table 3. Postoperative anteroposterior stability

\begin{tabular}{cc}
\hline & Value \\
\hline B point distance (cm) & \\
T0 (preoperatively) & $7.30 \pm 2.07$ \\
T1 (postoperatively) & $6.56 \pm 2.15$ \\
T2 (12-month follow-up) & $6.67 \pm 2.26$ \\
(T1, T0) & -2.713 \\
Z & $0.007 *$ \\
$P$-value & \\
(T1, T2) & -1.689 \\
Z & 0.1 \\
$P$-value & \\
(T2, T0) & -2.223 \\
Z & $0.026^{*}$ \\
$P$-value &
\end{tabular}

*Statistically significant, $P<0.05$.

Values are presented as mean \pm standard deviation.

$\mathrm{Z}$ value is based on the positive ranks.

Joo Young Lee et al: Sagittal split ramus osteotomy, intraoral vertical ramus osteotomy, and lateral corticectomy for asymmetric mandibular prognathism. J Korean Assoc Oral Maxillofac Surg 2021 the B point distance in T0, T1, and T2 for the 11 cases. The average B point distances for preoperative, postoperative, and at 12 months follow-up were $7.30 \mathrm{~cm}, 6.56 \mathrm{~cm}$, and 6.67 $\mathrm{cm}$, respectively, with a $0.11 \mathrm{~cm}$ mean difference between $\mathrm{T} 2$ and $\mathrm{T} 1$. B point distances for $\mathrm{T} 0$ and $\mathrm{T} 1$ were significantly different $(P=0.007)$, whereas those for $\mathrm{T} 1$ and $\mathrm{T} 2$ were not significantly different $(P=0.1)$. In addition, there was a significant difference between the $\mathrm{B}$ point distances of $\mathrm{T} 2$ and $\mathrm{T} 0(P=0.026)$. Because the $\mathrm{Z}$ value is based on positive ranks, $\mathrm{T} 0$ was greater than $\mathrm{T} 1$ and $\mathrm{T} 2$.

\section{Facial asymmetry}

Table 4 summarizes the values for indicators of facial asymmetry. On comparing the indicators for facial asymmetry before and after surgery, all five indicators demonstrated statistically significant differences between the S0 and $\mathrm{S} 1$; the $P$-values of Ag angle, $\mathrm{M}-\mathrm{Ag}, \mathrm{Co}-\mathrm{Ag}, \mathrm{Co}-\mathrm{Me}$, and AgMe were 0.003, 0.003, 0.008, 0.006, and 0.004, respectively. Because the $\mathrm{Z}$ value was based on negative ranks, S1 was

Table 4. Facial asymmetry indicators

\begin{tabular}{|c|c|}
\hline & Value \\
\hline \multicolumn{2}{|l|}{$\mathrm{Ag}$ angle $(\%)$} \\
\hline So & $91.95 \pm 4.08$ \\
\hline S1 & $98.44 \pm 1.06$ \\
\hline \multicolumn{2}{|l|}{ MSR-Ag (\%) } \\
\hline So & $83.22 \pm 6.41$ \\
\hline S1 & $94.90 \pm 4.48$ \\
\hline \multicolumn{2}{|l|}{ Co-Ag (\%) } \\
\hline So & $94.37 \pm 4.39$ \\
\hline $\mathrm{S} 1$ & $98.07 \pm 1.44$ \\
\hline \multicolumn{2}{|l|}{$\mathrm{Co}-\mathrm{Me}(\%)$} \\
\hline So & $93.64 \pm 3.71$ \\
\hline S1 & $98.22 \pm 1.01$ \\
\hline \multicolumn{2}{|l|}{ Ag-Me (\%) } \\
\hline So & $87.58 \pm 7.85$ \\
\hline $\mathrm{S} 1$ & $97.32 \pm 3.67$ \\
\hline \multicolumn{2}{|l|}{$(\mathrm{S} 1, \mathrm{~S} 0) \mathrm{Ag}$ angle } \\
\hline$P$-value & $0.003 *$ \\
\hline \multicolumn{2}{|l|}{ (S1, S0) MSR-Ag } \\
\hline Z & -2.934 \\
\hline$P$-value & $0.003 *$ \\
\hline \multicolumn{2}{|l|}{ (S1, S0) Co-Ag } \\
\hline $\mathrm{Z}$ & -2.667 \\
\hline$P$-value & $0.008 *$ \\
\hline \multicolumn{2}{|l|}{$(\mathrm{S} 1, \mathrm{~S} 0) \mathrm{Co}-\mathrm{Ag}$} \\
\hline $\mathrm{Z}$ & -2.756 \\
\hline$P$-value & $0.006^{*}$ \\
\hline \multicolumn{2}{|l|}{$(\mathrm{S} 1, \mathrm{~S} 0) \mathrm{Ag}-\mathrm{Me}$} \\
\hline$P$-value & $0.004 *$ \\
\hline
\end{tabular}

(S0: preoperatively, S1: 12-month follow-up, Ag: antegonion, MSR: mid-sagittal reference line, Co: condylion, Me: menton) * Statistically significant, $P<0.05$.

Values are presented as mean \pm standard deviation.

$\mathrm{Z}$ value is based on the negative ranks.

Joo Young Lee et al: Sagittal split ramus osteotomy, intraoral vertical ramus osteotomy, and lateral corticectomy for asymmetric mandibular prognathism. J Korean Assoc Oral Maxillofac Surg 2021 
greater than S0.

\section{Discussion}

The primary problem with orthognathic surgery is postoperative stability. Proffit et al. ${ }^{12}$ reported that this approach is problematic when the relapse rate is greater than $2 \mathrm{~mm}$. According to Jakobsone et al. ${ }^{13}$, relapse usually occurs within 6 months of orthognathic surgery. Based on this, we evaluated postoperative stability by measuring the B point distance before and after surgery and at the 12-month follow-up. Lai et al. ${ }^{9}$ evaluated postoperative relapse as the amount of change in B point distance after a combination surgery of SSRO and IVRO. They reported postoperative anteroposterior stability and no significant difference from that of BSSRO and bilateral IVRO (BIVRO).

In this study, we performed SSRO and IVRO combination surgeries and observed a significant difference in the B point distance between preoperation and postoperation and at the 12-month follow-up and preoperation. However, there was no significant difference in this distance between from postoperation to the 12-month follow-up, with an average difference of $0.11 \mathrm{~cm}$. Therefore, we assessed and observed anteroposterior stability after surgery.

IVRO is useful for addressing the gap problem for facial asymmetry because fixation is not needed. Therefore, postoperative stability was possible despite severe facial asymmetry. According to Beyer and Lindauer ${ }^{3}$, facial asymmetry occurs when the dental midline deviation is $2.2 \mathrm{~mm}$ or greater. We only included patients with a deviation of $2 \mathrm{~mm}$ or more in this study, which is consistent with the approach for previous studies $^{8,9,14}$.

Numerous analytic methods have been suggested for evaluating facial asymmetry, such as Rickett's method ${ }^{15}$ and Grummon's method ${ }^{16}$. Masuoka et al. ${ }^{5}$ reported that facial asymmetry becomes more severe from the maxilla to the mandible, especially in the menton, which is where the maximum deviation appears. In addition, menton deviation showed the greatest correlation with subjective judgment of facial asymmetry. Therefore, we focused on mandibular asymmetry and used effective indicators for evaluation, as presented by Grummon and Kappeyne van de Coppello ${ }^{16}$ and Lee et al. ${ }^{4}$. According to Hwang et al. ${ }^{17}$, antegonion and gonion can be used as reference points for evaluating mandibular asymmetry as well as reflection of changes in the soft tissue. Other studies also use these two reference points; however, according to Major et al. ${ }^{18}$, gonion is inaccurate as a reference point, and antegonion is more accurate than gonion. Therefore, we used antegonion in this study for accurately comparing facial asymmetries.

Surgical procedures performed to treat facial asymmetry include angle shaving, masseter resection, and cortical bone resection. Angle shaving is not an effective approach for resolving asymmetry because it requires bone resection, which increases asymmetry. Additionally, the approach is limited because the frontal profile after surgery is not significantly different from that before surgery ${ }^{19,20}$. Masseter resection usually is performed with angle shaving; however, it frequently is associated with hematoma and limited mouth-opening capacity as postoperative complications. In contrast, lateral corticectomy reduces the width of the mandible and changes the frontal profile. Therefore, to achieve sufficient frontal profile changes, lateral corticectomy should be performed instead of angle shaving ${ }^{21}$. According to Deguchi et al. ${ }^{20}$, because of postoperative masseter muscle atrophy, even lateral corticectomy without resection of the muscle results in a decreased width of the mandible, similar to that with angle shaving and masseter resection. Additionally, Han and $\mathrm{Kim}^{22}$ reported that, even without resecting the masseter muscle, the amount of reduction in the width of the mandible was similar to that of resection. However, nerve damage can occur because it has a bone resection line similar to that of SSRO.

In this study, we performed corticectomy on the IVRO side to resolve facial asymmetry. SSRO was performed at sites that could heal quickly due to contact between the cancellous bones with rigid internal fixation. However, when the evaluation is conducted through model surgery, an appropriate amount of bone is required for fixation on the SSRO side; hence, lateral corticectomy could not be performed sufficiently. On the contrary, because rigid internal fixation was not required on the IVRO side, we performed cortical bone resection to resolve facial asymmetry. Therefore, we efficiently improved the facial asymmetry using lateral corticectomy on the IVRO side.

Previous studies calculated asymmetry as the difference between the left and right measured values of facial characteristics $^{4,6,7}$. Although the difference in length affects the symmetry, the proportion of the difference(s) in the measured values between the left and right sides with respect to the mandible length can be small when the mandible is large. Therefore, evaluation of asymmetry by comparing ratios is a better method.

Facial asymmetry evaluation revealed a statistically significant difference between the preoperative and postoperative 
values for the five indicators. Because the $\mathrm{Z}$ value is based on negative ranks, postoperative values were higher than preoperative values. This suggests that the left and right sides become symmetrical as the value approaches $100 \%$, and facial asymmetry is improved.

The primary limitation of this study was the small number of cases, which required nonparametric statistics. When we performed nonparametric statistics, we did not calculate the difference between the mean values before and after surgery because only the increase or decrease in values was known. Therefore, compared with BSSRO and BIVRO, it was not possible to identify the most effective procedure for resolving facial asymmetry, and more cases are required for adequate comparison.

\section{Conclusion}

In this study, we achieved postoperative anteroposterior stability and improvement of facial asymmetry in patients with mandibular prognathism. The treatments included LeFort I osteotomy, SSRO, IVRO, and lateral corticectomy on the IVRO side. Based on the results, we determined that there was no significant difference in the B point distances at postoperation and at the 12-month follow-up; there were significant differences in all five indicators related to facial asymmetry before and after surgery, with all showing postoperative increase.

\section{ORCID}

Joo Young Lee, https://orcid.org/0000-0003-2520-6788

Se Jin Han, https://orcid.org/0000-0003-4949-4462

\section{Authors' Contributions}

J.Y.L. and S.J.H. participated in study design and data collection, performed the statistical analysis and wrote the manuscript.

\section{Ethics Approval and Consent to Participate}

This study was approved Institutional Review Board of Dankook Dental University Hospital (DKUDH IRB 2020-11004), and the informed consent was waived by the IRB.

\section{Consent for Publishing Photographs}

Written informed consent was obtained from the patients for publication of this article and accompanying images.

\section{Conflict of Interest}

No potential conflict of interest relevant to this article was reported.

\section{References}

1. Yun HJ. Effect of social pressure related to appearance and body image dissatisfaction on mental health in adolescents. J Korean Acad Soc Home Health Care Nurs 2020;27:92-101. https://doi. org/10.22705/jkashen.2020.27.1.92

2. Rhodes G, Proffitt F, Grady JM, Sumich A. Facial symmetry and the perception of beauty. Psychon Bull Rev 1998;5:659-69. https:// doi.org/10.3758/BF03208842

3. Beyer JW, Lindauer SJ. Evaluation of dental midline position. Semin Orthod 1998;4:146-52. https://doi.org/10.1016/s10738746(98)80016-9

4. Lee GH, Cho HK, Hwang HS, Kim JC. Studies of relationship between P-A cephalometric measurements and vidual facial asymmetry. Korean J Phys Anthropol 1998;11:41-8. https://doi. org/10.11637/kjpa.1998.11.1.41

5. Masuoka N, Momoi Y, Ariji Y, Nawa H, Muramatsu A, Goto S, et al. Can cephalometric indices and subjective evaluation be consistent for facial asymmetry? Angle Orthod 2005;75:651-5. https:// doi.org/10.1043/0003-3219(2005)75[651:CCIASE]2.0.CO;2

6. Rajpara Y, Shyagali TR, Trivedi K, Kambalyal P, Sha T, Jain V. Evaluation of facial asymmetry in esthetically pleasing faces. J Orthod Res 2014;2:79-84. https://doi.org/10.4103/2321-3825.131118

7. Vig PS, Hewitt AB. Asymmetry of the human facial skeleton. Angle Orthod 1975;45:125-9. https://doi.org/10.1043/00033219(1975)045<0125:AOTHFS $>2.0$. CO;2

8. Al-Gunaid T, Yamada K, Takagi R, Saito C, Saito I. Postoperative stability of bimaxillary surgery in Class III patients with mandibular protrusion and mandibular deviation: a frontal cephalometric study. Int J Oral Maxillofac Surg 2008;37:992-8. https://doi. org/10.1016/j.ijom.2008.05.018

9. Lai W, Yamada K, Hanada K, Ali IM, Takagi R, Kobayashi T, et al. Postoperative mandibular stability after orthognathic surgery in patients with mandibular protrusion and mandibular deviation. Int $\mathrm{J}$ Adult Orthodon Orthognath Surg 2002;17:13-22.

10. Lee JH, Park TJ, Jeon JH. Unilateral intraoral vertical ramus osteotomy and sagittal split ramus osteotomy for the treatment of asymmetric mandibles. J Korean Assoc Oral Maxillofac Surg 2015;41:102-8. https://doi.org/10.5125/jkaoms.2015.41.2.102

11. Lee SH, Chung DH, Cha KS, Lee JW, Lee SM. Orthognathic treatment using combination surgery (unilateral sagittal ramus osteotomy and unilateral intraoral vertical ramus osteotomy) for skeletal class III malocclusion patient with facial asymmetry. Clin J Korean Assoc Orthod 2019;9:178-88. https://doi.org/10.33777/ cjkao.2019.9.3.178

12. Proffit WR, Phillips C, Prewitt JW, Turvey TA. Stability after surgical-orthodontic correction of skeletal class III malocclusion. 2. Maxillary advancement. Int J Adult Orthodon Orthognath Surg 1991;6:71-80.

13. Jakobsone G, Stenvik A, Sandvik L, Espeland L. Three-year follow-up of bimaxillary surgery to correct skeletal class III malocclusion: stability and risk factors for relapse. Am J Orthod Dentofacial 
Orthop 2011;139:80-9. https://doi.org/10.1016/j.ajodo.2009.03.050

14. Al-Gunaid T, Yamaki M, Takagi R, Saito I. Soft and hard tissue changes after bimaxillary surgery in Japanese class III asymmetric patients. J Orthod Sci 2012;1:69-76. https://doi.org/10.4103/22780203.103865

15. Ricketts RM, Bench RW, Hilgers JJ, Schulhof R. An overview of computerized cephalometrics. Am J Orthod 1972;61:1-28. https:// doi.org/10.1016/0002-9416(72)90172-8

16. Grummons DC, Kappeyne van de Coppello MA. A frontal asymmetry analysis. J Clin Orthod 1987;21:448-65.

17. Hwang HS, Lee JJ, Hwang CH, Choi HH, Lim HJ. Prediction of frontal soft tissue changes after mandibular surgery in facial asymmetry individuals. Korean J Orthod 2008;38:252-64. https://doi. org/10.4041/kjod.2008.38.4.252

18. Major PW, Johnson DE, Hesse KL, Glover KE. Landmark identification error in posterior anterior cephalometrics. Angle Orthod 1994;64:447-54. https://doi.org/10.1043/00033219(1994)064<0447:LIEIPA >2.0.CO;2

19. Baek SM, Kim SS, Bindiger A. The prominent mandibular angle: preoperative management, operative technique, and results in 42 patients. Plast Reconstr Surg 1989;83:272-80.
20. Deguchi M, Iio Y, Kobayashi K, Shirakabe T. Angle-splitting ostectomy for reducing the width of the lower face. Plast Reconstr Surg 1997;99:1831-9. https://doi.org/10.1097/00006534-19970600000005

21. Jin $\mathrm{H}, \mathrm{Kim} \mathrm{BG}$. Mandibular angle reduction versus mandible reduction. Plast Reconstr Surg 2004;114:1263-9. https://doi. org/10.1097/01.prs.0000135904.40986.f8

22. Han K, Kim J. Reduction mandibuloplasty: ostectomy of the lateral cortex around the mandibular angle. J Craniofac Surg 2001;12:31425. https://doi.org/10.1097/00001665-200107000-00004

How to cite this article: Lee JY, Han SJ. Sagittal split ramus osteotomy, intraoral vertical ramus osteotomy, and lateral corticectomy for asymmetric mandibular prognathism. J Korean Assoc Oral Maxillofac Surg 2021;47:249-256. https://doi.org/10.5125/ jkaoms.2021.47.4.249 